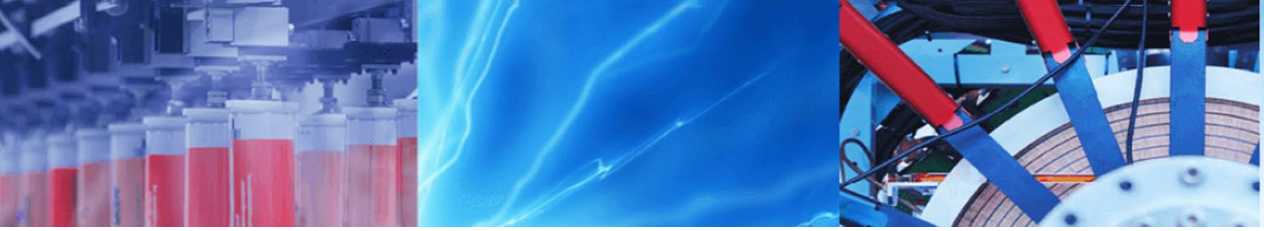

Research Article

\title{
Realization of time-dependent geocentric datum transformation parameters for Nigeria
}

\author{
Swafiyudeen Bawa ${ }^{1}$ D $\cdot$ Lazarus Mustapha Ojigi $^{1} \cdot$ Joseph Danasabe Dodo² $\cdot$ Kola M. Lawal ${ }^{3}$
}

(c) Springer Nature Switzerland AG 2019

\begin{abstract}
Geodetic reference frames were established decades ago by classical surveying techniques; however, due to biases caused by poor observation techniques and effects of plate tectonic, the origins are poorly defined and adopted. Due to plate tectonics, the relative position of points changes with time and therefore, datum such as MINNA requires redefinition at regular intervals to be in consonant with geodetic reference frame in use. Therefore, with the Continuously Operating Reference Stations (CORS) network in Nigeria, these biases can be mitigated and a more accurate datum transformation parameter between MINNA datum and ITRF can be developed and adopted. Therefore, this study presents the results of time-dependent datum transformation parameters proposed for Nigeria using 5-years GNSS data (from 2011 to 2015) obtained from the NigNet CORS. GAMIT GNSS scientific processing software was deployed in processing, while GLOBK was used for frame definition and datum transformation parameters development. Statistical assessments show the validity of the transformation parameters. The correlation value was found to be 1, root mean square error 0.00411 , normalized mean absolute error $1.267 \mathrm{E}-10$ and reliability index 1.0 .
\end{abstract}

Keywords Datum $\cdot$ Geocentric $\cdot$ Nigeria $\cdot$ Transformation parameters

\section{Introduction}

In recent years, the positional accuracy attainable from GNSS technology is at a millimetre level [10]. With this accuracy, coordinates change in a high pace over time due to plate tectonic motion and other geophysical phenomenon. Current and previous International Terrestrial Reference Frame (ITRF) realizations take into account tectonic plate motion and other deformation such as earthquakes. Therefore, coordinates of points with every new realization of ITRF change even at a later epoch of same realization.

The coordinates of geodetic datum are the fundamentals for positioning. However, GIS and surveying software as well as spatial data do not consider continuous changes in coordinates, meaning that national datum and coordinates are assumed fixed with time. Similarly, geodetic networks are known to form the basis of investigating the shape, dimension and in many cases the gravity field of the earth $[10,26]$. Therefore, positioning is a major stakeholder in modern day society in that it is of interest in navigation and guidance, datum realization, crustal deformation, plate tectonic studies, amongst others.

Geodetic datums are curved reference surfaces used to express position with adopted ellipsoid of revolution, size and shape [10,29]. Generally, local geodetic datums whose ellipsoid does not coincide with the earth's centre of mass and geocentric datum whose ellipsoid coincides with the earth's centre of mass are the two fundamental categories of geodetic datum [10]. Geodetic datum can be static, dynamic and semi-dynamic $[9,25,27]$. Traditional geodetic datums are assumed static in nature. This is because they consider the constantly changing earth to

Swafiyudeen Bawa, bswafiyudeen@gmail.com | ${ }^{1}$ Department of Geomatics, Ahmadu Bello University, Zaria, Kaduna, Nigeria. ${ }^{2}$ Centre for Geodesy and Geodynamics, NASRDA, Toro, Bauchi State, Nigeria. ${ }^{3}$ Department of Physics, Ahmadu Bello University, Zaria, Kaduna, Nigeria.

SN Applied Sciences (2019) 1:713 | https://doi.org/10.1007/s42452-019-0711-1 
be static which is very untrue because they are affected by geological and tectonic activities.

Dynamic datum, on the other hand, is a function of time. This means that coordinates vary with time. Example of a dynamic datum is the ITRF $[2,3]$. Therefore, to take into account the changing earth, the ITRF is updated after every 5 years to accommodate advances in processing and data improvement. Implementation of a dynamic datum is a very difficult task at national a level. This has to be done monthly or weekly, thereby making the choice of the correct epoch for referencing observation extremely complex [13].

Semi-dynamic datum considers the constantly changing earth's motion, but coordinates are referred to a single reference epoch $[9,25,27]$. Coordinates in a semi-dynamic datum can be propagated from the pre-defined reference epoch to an epoch of interest. What needs update is the deformation model.

Rapid advances in space-geodetic technique such as GNSS, very-long-baseline interferometry (VLBI), Global Navigation Satellite System (GNSS), Doppler Orbitography and Radiopositioning Integrated by Satellite (DORIS) and their found application in geodesy and geomatics have led to a significant improvement in modern positioning and allied applications. The tectonic motion of the NUBIA plate which might result in volcanism, earthquakes and earth tremors and other deformation sources such as subsidence and soil creep [10] and un-modelled measurement biases [6] affect geodetic infrastructure (e.g. NigNet), and therefore, decrease the accuracy of reference station coordinates, thereby leading to inconsistencies in legal traceability of coordinates of NigNet coordinates over time [11].

Since the MINNA datum for Nigeria was realized based on classical methods of surveying, it is known to be subjected to biases as a result of poor observations and techniques [8]. Also, Nigerian MINNA datum is faced with biases such as inaccuracies of the scale factor by compression of the Clarke 1880, poor definition of origin, geoidal height model absence and difficulty in datum parameters determination [30]. Therefore, with these inherent errors, there is the need to move away from the still-in-use MINNA datum and adopt a new datum that is geocentric in nature as done in countries like Australia (GDA2020), China (CTRF2000), Indonesia (DGN1995), Malaysia (GDM2000), New Zealand (NZGD2000), USA (NAD83), amongst others [7, 20]. Studies of $[5,8,12,18,25]$ further justify the need for this study, in that coordinates of points anywhere in the world will change with time. Therefore, by integrating velocity, epoch and episodic deformation information, locations of points can be kept on track. Therefore, this study presents and proposes a new time-dependent geocentric datum transformation parameters for Nigeria by processing 5 years (2011-2015) of the 14 NigNet tracking stations (Fig. 1) [19] and 9 IGS stations (Fig. 2) [22] using GAMIT for producing

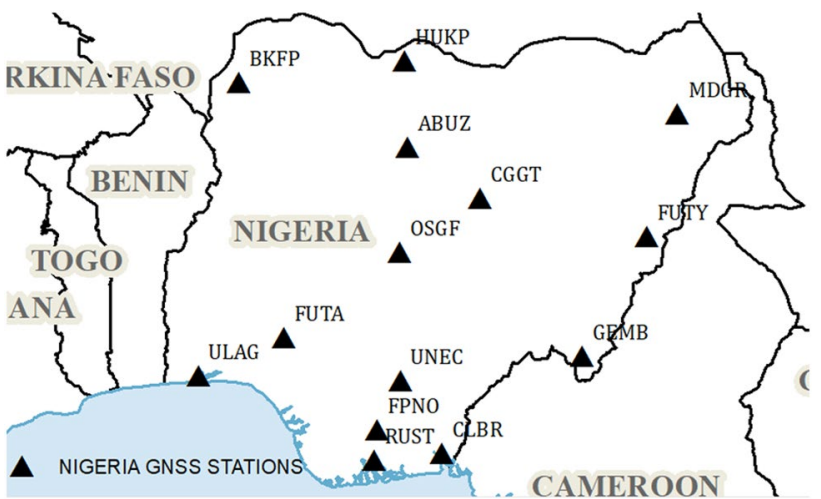

Fig. 1 Spatial distribution of NiGNet tracking stations with the station at KANO excluded

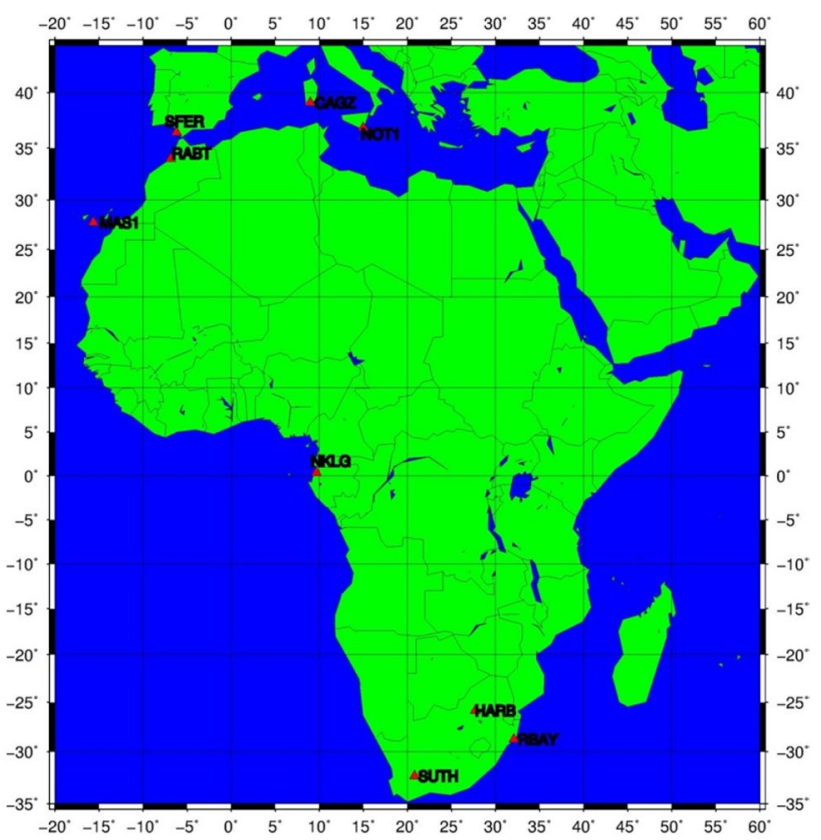

Fig. 2 Spatial distribution of IGS stations adopted for the study

loose constrain estimate of position and covariance matrix and GLOBK for reference frame definition.

\section{Need for transformation parameters and coordinate update in Nigeria}

With series of earth tremor occurrences in Nigeria, epochby-epoch realization of ITRF is essential so that spatial data of global, local, national and regional origin can be integrated with ease. Over the years, the development of transformation parameters for Nigeria particularly, the classical transformation which involves 7-parameter similarity (Helmert) transformation, has been met with several

\section{SN Applied Sciences}


technical challenges such as inaccuracies of the scale factor by compression of the Clarke 1880, poor definition of origin, geoidal height model absence and difficulty in datum parameters determination as highlighted earlier. However, with the evolution of ITRF, the 7-parameter transformation has extended to 14-parameter transformation. The additional 7 parameters describe the transition of the initial 7 parameters with time [20]. Furthermore, depending on the need, surveys in Nigeria are reported in various coordinates that include Nigeria Transverse Mercator Projection (NTM), MINNA, World Geodetic System 1984 (WGS84) and ITRF. Ensuring the compatibility and uniformity of coordinates, [7] reported that the use of different coordinate system poses danger and a difficult task to achieve.

Therefore, the optimum way to achieve centimetrelevel accuracy is to relate GNSS measurements to ITRF. Therefore, ITRF-based transformation parameters will go a long way towards realization of centimetre accuracy since deformation of the earth is taken into cognisance.

Most importantly, with modern space-geodetic techniques, such as the GNSS CORS network in Nigeria, the biases due to classical observational techniques and the phenomenon of plate tectonic motion can be mitigated and a more accurate geocentric datum transformation parameters between MINNA DATUM and the known ITRF can be developed and adopted. This study therefore aims at proposing time-dependent geocentric datum transformation parameters for Nigeria using 5-year (2011-2015) NigNet GNSS CORS data.

\section{Materials and method}

\subsection{Test site description}

In Nigeria, an initiative to establish a Continuously Operating Reference Stations (CORS) called NIGerian Reference GNSS NETwork (NIGNET) (see Fig. 1) which is a network of
Continuous GNSS stations kicked off in 2008 by Office of the Surveyor General of the Federation (OSGoF). The initiative was aimed at contributing to the African Reference Frame (AFREF) and serve as a primary fiducial network that will define and materialize a new reference frame based on space-geodetic technique [19]. The study area is Nigeria located on the western part of Africa Plate between latitude $4^{\circ}$ and $14^{\circ} \mathrm{N}$ and longitude $2^{\circ}$ and $15^{\circ} \mathrm{E}$. The details of the dataset used for this study are presented in Table 1. The spatial distribution of the NigNet and IGS stations used for the study is presented in Figs. 1 and 2, respectively.

\subsection{GNSS data processing}

GAMIT/GLOBK software release 10.6 was used for processing [14-16]. GAMIT/GLOBK is a comprehensive GNSS analysis package developed at Massachusetts Institute of Technology (MIT), the Harvard Smithsonian Center for Astrophysics (CFA) and the Scripps Institute of Oceanography (SIO) for estimating station coordinate and velocities, stochastic or functional representation of post-seismic deformations, atmospheric delays, satellite orbits and Earth orientation parameters [15, 32].

Depending on the task at hand, processing in GAMIT can be in single session or automatic batch processing (invoked when there is considerable large amount of data or multiple session of data and time is needed to be saved) using scripts for example sh_gamit in GAMIT or sh_glred in GLOBK. In the automatic batch processing, which was adopted in this study, the only preparation is assembling and preparation of control files like sestbl, sittbl, station.info, session.info, etc. Models applied to account for dynamic factors include Vienna Mapping Function (VMF1) for tropospheric mapping of dry and wet mapping function, FES2004 ocean tide loading model and IERSO3 solid earth tide model.

The results obtained in automatic batch processing of GAMIT are generally loose constrain estimate of position

Table 1 Summary of dataset and sources adopted for the study

\begin{tabular}{|c|c|c|c|}
\hline $\mathrm{S} / \mathrm{N}$ & Dataset(s) & Source(s) & Purpose(s) \\
\hline 1 & $\begin{array}{l}\text { RINEX files associated with } 14 \text { selected NigNet } \\
\text { tracking stations from } 1 \text { January } 2011 \text { to } 31 \\
\text { December } 2015 \text { (1826 days) }\end{array}$ & www.nignet.net & $\begin{array}{l}\text { Time series analysis, position and velocity esti- } \\
\text { mate and strain computation }\end{array}$ \\
\hline 2 & $\begin{array}{l}\text { Nine international GNSS services (IGS) stations } \\
\text { from } 1 \text { January } 2011 \text { to } 31 \text { December } 2015 \\
\text { (1826 days) }\end{array}$ & ftp://cddis.gsfc.nasa.gov & Position, velocity and frame realization \\
\hline 3 & SP3 precise ephemeris orbits & http://cddis.nasa.gov & For GAMIT/GLOBK processing \\
\hline 4 & Ocean tide loading model (FES2004) & ftp://everest.mit.edu/pub/GRIDS & Correction for ocean tide loading \\
\hline 5 & Dry and wet Mmpping function (VMF1) & ftp://everest.mit.edu/pub/GRIDS & $\begin{array}{l}\text { Incorporate and estimate tropospheric delay for } \\
\text { both dry and wet mapping function }\end{array}$ \\
\hline 6 & $\begin{array}{l}\text { Atmospheric tidal loading (ATL) and non-tidal } \\
\text { atmospheric loading (ATML) }\end{array}$ & ftp://everest.mit.edu/pub/GRIDS/ & $\begin{array}{l}\text { Correction for tidal and non-tidal atmospheric } \\
\text { loading }\end{array}$ \\
\hline
\end{tabular}


and covariance matrix associated with a survey station. Table 2 depicts the processing parameters adopted for this study. The ASCII h-files containing loose-constrained weighted least squares estimate of sites coordinates and variance-covariance produced by GAMIT are converted to binary $\mathrm{H}$-files readable by GLOBK to produce time series, velocity and reference frame definition.

\subsection{Reference frame definition}

Frame realization was carried out in GLOBK by adopting the International Terrestrial Reference Frame (ITRF) as global constraints. In this study, solutions from GAMIT were constrained to ITRF2008 [2] and ITRF2014 [3] while estimating seven Helmert parameters ( 3 translation, 3 rotation and 1 scale) and their respective rates for each solution from GAMIT analysis. The study constrained NigNet tracking stations to global stations consisting of 9 selected IGS (see, for example, Fig. 2) sites in ITRF2008 and ITRF2014 using GLOBK. The solutions from GLOBK include velocity solution, reference frame and Euler plate motion parameters, amongst others.

\subsection{Coordinates transformation method}

Transformation of GNSS coordinate time series from one reference frame to another can be realized with Helmert 14-parameter or 7-parameter transformation. The Helmert 14-parameter was adopted for this study. These include 3 translations (which affects position of coordinate origin), 3 rotations (which affects orientation of coordinate axes) and 1 scale (affects length of coordinate axes), and their rates (achievable with a velocity model). The Euclidian similarity 14-parameter datum transformation model (Eqs. 1a-1c) which includes three rotations, $T_{x}(t), T_{y}(t)$, $T_{z}(t)$, three translation $\left(R_{x}(t) R_{y}(t) R_{z}(t)\right)$ and a scale factor $S_{c}(t)[6,10,31]$, was adopted and tested to transform station coordinates and respective velocities at epoch 2015.9685 (2015/12/20) from ITRF08 and ITRF14 to a proposed Geocentric Datum of Nigeria (GDN). Though, Euler plate motion parameters can also be used [26].

$$
\begin{aligned}
X(t)_{\mathrm{GDN}}= & T_{x}(t)+[1+s(t)] X(t)_{\operatorname{TRRF}_{y y}} \\
& +R_{z}(t) Y(t)_{\operatorname{ITRF}_{y y}}-R_{y}(t) Z_{\mathrm{TRRF}_{y y}} \\
Y(t)_{\mathrm{GDN}}= & T_{y}(t)-R_{z}(t) X(t)_{\operatorname{TRRF}_{y y}} \\
& +[1+s(t)] Y(t)_{\operatorname{TRF}_{y y}}+R_{x}(t) Z(t)_{\operatorname{TRRF}_{y y}} \\
Z(t)_{\mathrm{GDN}}= & T_{z}(t)+R_{y}(t) X(t)_{\operatorname{TRF}_{y y}} \\
& +[1+s(t)] Z(t)_{\operatorname{TRRF}_{y y}}-R_{x}(t) Y(t)_{\operatorname{TRF}_{y y}}
\end{aligned}
$$

The time-related variations are assumed to be linear; therefore, the quantities can be expressed by Eq. (2) [23, 24]. Equation (2) is inputted into Eq. (1) to finally get a 7-parameter transformation model.

$$
\begin{aligned}
& T_{x}=t_{x}\left(t_{0}\right)+\dot{t}_{x}\left(t-t_{0}\right) \\
& T_{y}=t_{y}\left(t_{0}\right)+\dot{t}_{y}\left(t-t_{0}\right) \\
& T_{z}=t_{z}\left(t_{0}\right)+\dot{t}_{z}\left(t-t_{0}\right) \\
& S_{c}=s_{c}\left(t_{0}\right)+\dot{s}_{c}\left(t-t_{0}\right) \\
& R_{x}=r_{x}\left(t_{0}\right)+\dot{r}_{x}\left(t-t_{0}\right) \\
& R_{y}=r_{y}\left(t_{0}\right)+\dot{r}_{y}\left(t-t_{0}\right) \\
& R_{z}=r_{z}\left(t_{0}\right)+\dot{r}_{z}\left(t-t_{0}\right)
\end{aligned}
$$

Table 2 Basic processing parameters [4]

\begin{tabular}{ll}
\hline Parameter(s) & Description \\
\hline RINEX data & 30 s sampling rate \\
Orbital data & IGS final/precise orbit \\
Ocean tide loading & FES2004 \\
lonospheric model & Double-difference ionospheric-free (IF) linear combination \\
Adjustment & Kalman filter \\
Tropospheric delay model & Saastamoinen model \\
Elevation cut-off & $10^{\circ}$ \\
Antenna model & ELEV \\
Earth tide model & IERS03 \\
Choice of experiment & Baseline \\
Dry and wet mapping function & New Vienna Mapping Function (VMF1) \\
Atmospheric tidal loading (ATL) and non-tidal atmospheric loading (ATML) & Yes \\
Observations & 30 -s sampling interval \\
Satellite orbits/earth orientation parameters & IGS final orbits (SP3) and IGS final EOP products \\
Meteorological observation source & VMF1 \\
\hline
\end{tabular}


where the 7 Helmert parameters $r_{x}\left(t_{0}\right), r_{y}\left(t_{0}\right), r_{z}\left(t_{0}\right)\left(t_{x}\left(t_{0}\right)\right.$, $t_{y}\left(t_{0}\right), t_{z}\left(t_{0}\right)$ and $\left.s_{c}\left(t_{0}\right)\right)$ are rotations, translation and scale parameters in the position domain, respectively, at a reference epoch, which are constant. Their respective first time derivations in the rate domain are $\dot{t}_{x}, \dot{t}_{y}, \dot{t}_{z}, \dot{r}_{x}, \dot{r}_{y}, \dot{r}_{z}$ and $\dot{s}_{c}$. The Helmert parameters and their first time derivatives are obtained by invoking a generalized constraint in glorg module of GLOBK.

\subsection{Test statistics for validating transformation parameters}

The accuracy, precision and reliability of the newly obtained transformation parameters were evaluated using standard model performance indicators. The normalized mean absolute error (NMEA) [28], root mean square error (RMSE), reliability index (RI) [21] and correlation coefficient $(r)$ are given in Eqs. (3)-(6) [17].

$$
\begin{aligned}
& \text { NMAE }=\frac{\sum_{i=1}^{n}\left(\mid \text { residuals }_{i} \mid\right)}{n \bar{o}} \\
& \text { RMSE }=\sqrt{\frac{\sum_{i=1}^{n}\left(\text { residuals }_{i}\right)^{2}}{n}} \\
& \mathrm{RI}=\sqrt[\exp ]{\frac{\sum_{i=n}^{n}\left(\log \frac{o_{i}}{p_{i}}\right)^{2}}{n}} \\
& r=\frac{\sum_{i=1}^{n}\left(p_{i}-\bar{p}\right)\left(o_{i}-\bar{o}\right)}{\left[\sum_{i=n}^{n}\left(p_{i}-\bar{p}\right)^{2} \sum_{i=1}^{n}\left(o_{i}-\bar{o}\right)^{2}\right]^{1 / 2}}
\end{aligned}
$$

where $n$ is the number of NigNet tracking stations used,

\begin{tabular}{|c|c|c|c|c|c|c|c|}
\hline $\begin{array}{l}\text { ITRFyy } \\
\text { Rates }\end{array}$ & $\begin{array}{l}t_{x}(\mathrm{~mm}) \\
\dot{t}_{x}(\mathrm{~mm} / \text { year })\end{array}$ & $\begin{array}{l}t_{y}(\mathrm{~mm}) \\
\dot{t}_{y}(\mathrm{~mm} / \text { year })\end{array}$ & $\begin{array}{l}t_{z}(\mathrm{~mm}) \\
\dot{t}_{z}(\mathrm{~mm} / \text { year })\end{array}$ & $\begin{array}{l}s_{c}(\mathrm{ppb}) \\
\dot{s}_{c}(\mathrm{ppb} / \text { year })\end{array}$ & $\begin{array}{l}r_{x} \text { (mas) } \\
\dot{r}_{x} \text { (mas/year) }\end{array}$ & $\begin{array}{l}r_{y} \text { (mas) } \\
\dot{r}_{y} \text { (mas/year) }\end{array}$ & $\begin{array}{l}r_{z} \text { (mas) } \\
\dot{r}_{z} \text { (mas/year) }\end{array}$ \\
\hline ITRF08 & $2.10 \pm 0.00$ & $-4.96 \pm 0.00$ & $3.71 \pm 0.00$ & $-0.862 \pm 0.302$ & $6.3947 \pm 0.1110$ & $42.7931 \pm 0.0410$ & $-7.5334 \pm 0.1910$ \\
\hline Rates & $-7.0 \pm 0.0004$ & $3.4 \pm 0.0013$ & $3-0.89 \pm 0.0009$ & $0.528 \pm 0.0863$ & $-0.3467 \pm 0.0301$ & $0.1222 \pm 0.0116$ & $0.3385 \pm 0.0507$ \\
\hline ITRF14 & $1.23 \pm 0.00$ & $-2.02 \pm 0.00$ & $6.66 \pm 0.00$ & $-0.141 \pm 0.157$ & $6.5439 \pm 0.0558$ & $47.2092 \pm 0.0211$ & $-7.8789 \pm 0.0979$ \\
\hline Rates & $-7.0 \pm 0.00027$ & $3.4 \pm 0.00080$ & $0-0.89 \pm 0.00056$ & $0.322 \pm 0.05184$ & $-0.0304 \pm 0.01786$ & $-0.0944 \pm 0.00701$ & $-0.0844 \pm 0.03023$ \\
\hline
\end{tabular}
residuals $=p_{i}-o_{i}$ and $o_{i}$ and $p_{i}$ are the $i$ th computed and

Table 3 Summary of ITRF08 and ITRF14 to geocentric datum of Nigeria 2015 (GDN15) transformation parameters and their uncertainties at reference epoch 2015.9685

\begin{tabular}{|c|c|c|c|c|c|c|}
\hline \multicolumn{4}{|c|}{ ITRF08 at epoch 2015.9685} & \multicolumn{3}{|c|}{ ITRF14 at epoch 2015.9685} \\
\hline Station & $X(\mathrm{~m})$ & $Y(\mathrm{~m})$ & $Z(\mathrm{~m})$ & $X(\mathrm{~m})$ & $Y(\mathrm{~m})$ & $Z(\mathrm{~m})$ \\
\hline MDGR & $6,080,449.24413$ & $1,418,433.59502$ & $1,299,949.51341$ & $6,080,449.24930$ & $1,418,433.59434$ & $1,299,949.51197$ \\
\hline FUTY & $6,145,058.44928$ & 1,362,078.97999 & $1,029,390.00286$ & $6,145,058.45130$ & $1,362,078.97935$ & $1,029,390.00254$ \\
\hline GEMB & $6,213,520.30484$ & $1,228,500.48,824$ & $763,261.05312$ & $6,213,520.30668$ & $1,228,500.48737$ & $763,261.05293$ \\
\hline CGGT & $6,201,032.23378$ & $995,277.36236$ & $1,113,815.58849$ & $6,201,032.23677$ & $995,277.36246$ & $1,113,815.58791$ \\
\hline CLBR & $6,287,174.18547$ & $922,979.55290$ & $546,713.85390$ & $6,287,174.18627$ & $922,979.55197$ & $546,713.85325$ \\
\hline$A B U Z$ & $6,203,493.78641$ & $833,088.80383$ & $1,225,614.72227$ & $6,203,493.78850$ & $833,088.80337$ & $1,225,614.72216$ \\
\hline HUKP & $6,163,727.05738$ & $821,421.99098$ & $1,417,029.88278$ & $6,163,727.05973$ & $821,421.99077$ & $1,417,029.88284$ \\
\hline UNEC & $6,284,298.27701$ & $827,900.62128$ & $708,988.67915$ & $6,284,298.27866$ & $827,900.62052$ & $708,988.67908$ \\
\hline OSGF & $6,246,471.22824$ & $820,848.83991$ & $994,268.02177$ & $6,246,471.22987$ & $820,848.83931$ & $994,268.02167$ \\
\hline FPNO & $6,301,965.77800$ & $777,495.46754$ & $600,049.71461$ & $6,301,965.77942$ & $777,495.46716$ & $600,049.71555$ \\
\hline RUST & $6,308,859.02071$ & $772,230.02159$ & $530,354.55584$ & $6,308,859.04088$ & $772,230.02224$ & $530,354.54541$ \\
\hline FUTA & $6,301,798.91397$ & $566,460.90180$ & $804,956.62950$ & $6,301,798.91615$ & $566,460.90087$ & $804,956.62955$ \\
\hline BKFP & $6,211,960.31340$ & $459,365.58393$ & $1,368,115.13291$ & $6,211,960.31551$ & $459,365.58363$ & $1,368,115.13312$ \\
\hline ULAG & $6,326,097.27163$ & $375,576.21698$ & $719,131.77913$ & $6,326,097.27336$ & $375,576.21624$ & $719,131.77930$ \\
\hline
\end{tabular}

mas milli-arc seconds, ppb parts per billion

Table 4 Geocentric (ECEF) coordinates of NigNet in ITRF08 and ITRF14 at epoch 2015.9685 
model estimated. Similarly, $\bar{o}$ and $\bar{p}$ are the mean computed and model estimates.

\section{Results and analysis}

\subsection{Results}

While estimating translation, rotation and scale (Helmert parameters) in GLOBK, a rigorous approach of frame definition was realized through a generalized constraints, where the study minimized the adjustments of coordinates of the frame-defining sites [15] as discussed earlier in Sect. 3.4. By minimizing the adjustment of coordinates of the frame-defining sites, all of the reference sites are free to adjust, thereby revealing bad data or coordinates solutions. Table 3 shows the summary of the time-dependent geocentric transformation parameters for Nigeria.

Similarly, Tables 4 and 5 are the coordinate solutions of the adopted NigNet stations in earth-centred earth-fixed (ECEF) and geodetic coordinate system, respectively. The residuals plots of the two coordinates systems in both reference frames are presented in Fig. 3a, b, with station RUST having the highest residual. The reason for this high residual is unknown in the present study. Probably, bad stabilization might be the cause, but the post-root mean square error (post-RMS) in ITRF14 for velocity and position system stabilization yielded $0.029 \mathrm{~mm} /$ year and $0.087 \mathrm{~mm}$, respectively. In ITRF08, the post-root mean square error (post-RMS) for velocity and position system stabilization yielded $0.049 \mathrm{~mm} /$ year and $0.016 \mathrm{~mm}$, respectively. [15] recommended value of $1-5 \mathrm{~mm}$ for position system
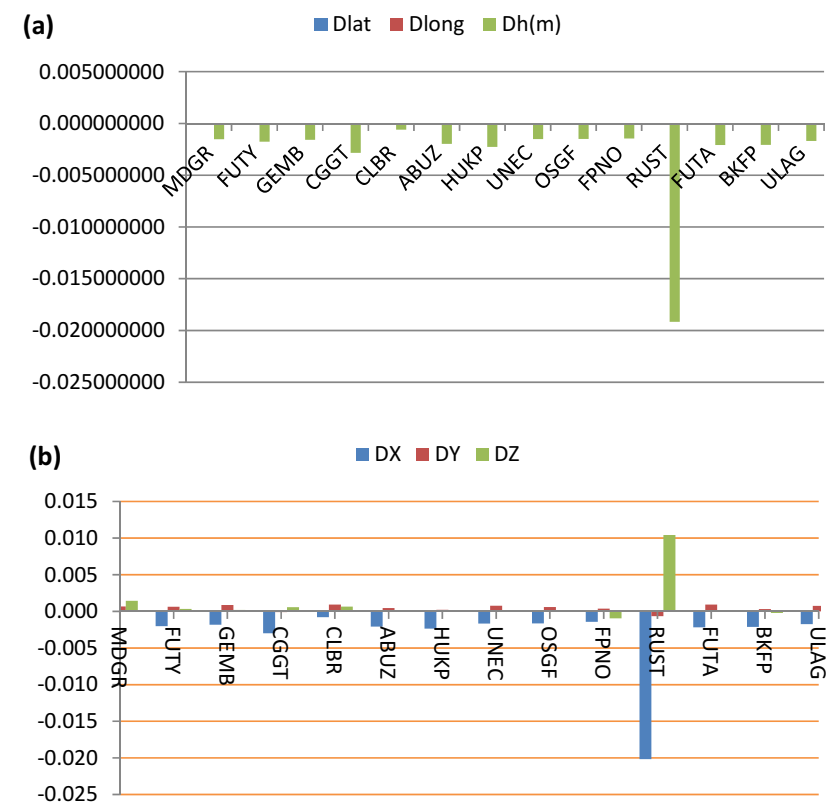

Fig. 3 Residual plot of coordinate of a (in ECEF, Table 4) solutions in ITRF08 and ITRF14; b (in geodetic, Table 5) solutions in ITRF08 and ITRF14

stabilization. Therefore, bad stabilization is written off as the cause.

\subsection{Analysis}

To this end, Tables 4 and 5 present the geocentric and geodetic coordinates of the NigNet GNSS stations at epoch 2015.9685, respectively. Furthermore, the timedependent 14-parameter datum transformation relation
Table 5 Geodetic coordinates of NigNet in ITRF08 and ITRF14 at epoch 2015.9685

\begin{tabular}{|c|c|c|c|c|c|c|}
\hline \multicolumn{4}{|c|}{ ITRF08 at epoch 2015.9685} & \multicolumn{3}{|c|}{ ITRF14 at epoch 2015.9685} \\
\hline Station & Lat $\left({ }^{\circ}\right)$ & $\operatorname{Lon}\left({ }^{\circ}\right)$ & $h(\mathrm{~m})$ & $\operatorname{Lat}\left({ }^{\circ}\right)$ & $\operatorname{Lon}\left({ }^{\circ}\right)$ & $h(\mathrm{~m})$ \\
\hline MDGR & 11.8380913021 & 13.1310026973 & 348.23460 & 11.8380912803 & 13.1310026805 & 348.23613 \\
\hline FUTY & 9.3497435023 & 12.4977988278 & 247.39244 & 9.3497434968 & 12.4977988182 & 247.39420 \\
\hline GEMB & 6.9172002414 & 11.1839415016 & 1795.64560 & 6.9172002378 & 11.1839414906 & 1795.64719 \\
\hline CGGT & 10.1230954562 & 9.1183128390 & 916.43041 & 10.1230954464 & 9.1183128355 & 916.43324 \\
\hline CLBR & 4.9503019072 & 8.3515696770 & 57.17408 & 4.9503019008 & 8.3515696676 & 57.17468 \\
\hline$A B U Z$ & 11.1517407664 & 7.6486883103 & 705.06138 & 11.1517407619 & 7.6486883036 & 705.06334 \\
\hline HUKP & 12.9211546183 & 7.5909143745 & 559.61850 & 12.9211546142 & 7.5909143697 & 559.62076 \\
\hline UNEC & 6.4248068753 & 7.5049922697 & 254.39541 & 6.4248068731 & 7.5049922610 & 254.39693 \\
\hline OSGF & 9.0276667059 & 7.4863427013 & 532.64337 & 9.0276667028 & 7.4863426940 & 532.64487 \\
\hline FPNO & 5.4345731482 & 7.0332392250 & 88.31087 & 5.4345731555 & 7.0332392200 & 88.31232 \\
\hline RUST & 4.8018369060 & 6.9785222775 & 45.57414 & 4.8018367969 & 6.9785222612 & 45.59330 \\
\hline FUTA & 7.2986402623 & 5.1364422289 & 410.58464 & 7.2986402604 & 5.1364422188 & 410.58673 \\
\hline BKFP & 12.4685775715 & 4.2292431369 & 250.00403 & 12.4685775694 & 4.2292431328 & 250.00611 \\
\hline ULAG & 6.5173274203 & 3.3976244443 & 44.55984 & 6.5173274201 & 3.3976244367 & 44.56153 \\
\hline
\end{tabular}


Table 6 Transformed geocentric (ECEF) coordinates of NigNet in ITRF08 to epoch 2011.00 using that obtained from OSGoF

\begin{tabular}{|c|c|c|c|c|c|c|}
\hline \multirow[t]{2}{*}{ Stations } & \multicolumn{3}{|c|}{ Coordinates from parameters to epoch 2011.00} & \multicolumn{3}{|c|}{ Coordinates from OSGOF epoch 2011.00} \\
\hline & $X(\mathrm{~m})$ & $Y(\mathrm{~m})$ & $Z(\mathrm{~m})$ & $X(\mathrm{~m})$ & $Y(\mathrm{~m})$ & $Z(\mathrm{~m})$ \\
\hline MDGR & $6,080,449.01428$ & $1,418,433.39115$ & $1,299,949.72885$ & $6,080,449.31020$ & $1,418,433.50620$ & $1,299,949.42040$ \\
\hline FUTY & $6,145,058.26851$ & $1,362,078.76812$ & $1,029,390.22314$ & $6,145,058.48550$ & $1,362,078.88210$ & $1,029,389.91230$ \\
\hline GEMB & $6,213,520.17239$ & $1,228,500.26810$ & $763,261.27930$ & $6,213,520.30540$ & $1,228,500.38660$ & $763,260.95600$ \\
\hline CGGT & $6,201,032.02147$ & $995,277.14949$ & $1,113,815.81819$ & $6,201,032.26630$ & $995,277.24960$ & $1,113,815.51850$ \\
\hline CLBR & $6,287,174.08361$ & $922,979.32514$ & $546,714.08852$ & $6,287,174.16330$ & $922,979.44880$ & $546,713.76520$ \\
\hline ABUZ & $6,203,493.54500$ & $833,088.59306$ & $1,225,614.95558$ & $6,203,493.81020$ & $833,088.70460$ & $1,225,614.62980$ \\
\hline UNEC & $6,284,298.13870$ & $827,900.39694$ & $708,988.91515$ & $6,284,298.29670$ & $827,900.51990$ & $708,988.58530$ \\
\hline OSGF & $6,246,471.03300$ & $820,848.62272$ & $994,268.25665$ & $6,246,471.24960$ & $820,848.74400$ & $994,267.92810$ \\
\hline RUST & $6,308,858.93534$ & $772,229.79475$ & $530,354.78307$ & $6,308,859.04250$ & $772,229.93130$ & $530,354.45830$ \\
\hline BKFP & $6,211,960.02844$ & $459,365.37528$ & 1,368,115.37451 & $6,211,960.33600$ & $459,365.48270$ & $1,368,115.04300$ \\
\hline ULAG & $6,326,097.11517$ & $375,575.99096$ & $719,132.02554$ & 6,326,097.29100 & $375,576.11170$ & $719,131.68930$ \\
\hline
\end{tabular}

Table 7 Transformed geodetic coordinates of NigNet in ITRF08 to epoch 2011.00 using that obtained from OSGoF

\begin{tabular}{|c|c|c|c|c|c|c|}
\hline & \multicolumn{3}{|c|}{$\begin{array}{l}\text { Coordinates from parameters to epoch } \\
2011.00\end{array}$} & \multicolumn{3}{|c|}{ Coordinates from OSGF epoch 2011.00} \\
\hline & Lat $\left({ }^{\circ}\right)$ & Long $\left(^{\circ}\right)$ & $h(\mathrm{~m})$ & $\overline{\operatorname{Lat}\left({ }^{\circ}\right)}$ & Long $\left({ }^{\circ}\right)$ & $h(\mathrm{~m})$ \\
\hline MDGR & 11.8380913018 & 13.13100269731 & 348.232 & 11.8380903963 & 13.1310017662 & 348.256 \\
\hline FUTY & 9.3497435186 & 12.49779883391 & 247.390 & 9.3497426732 & 12.4977978863 & 247.392 \\
\hline GEMB & 6.9172002632 & 11.18394150575 & 1795.643 & 6.9171993891 & 11.1839405985 & 1795.615 \\
\hline CGGT & 10.1230954707 & 9.11831284289 & 916.428 & 10.1230948094 & 9.1183117765 & 916.432 \\
\hline CLBR & 4.9503019252 & 8.35156968042 & 57.171 & 4.9503011371 & 8.3515687778 & 57.130 \\
\hline$A B \cup Z$ & 11.1517407832 & 7.64868831494 & 705.059 & 11.1517399270 & 7.6486873808 & 705.054 \\
\hline UNEC & 6.4248068890 & 7.50499227431 & 254.392 & 6.4248060252 & 7.5049913378 & 254.391 \\
\hline OSGF & 9.0276667198 & 7.48634270492 & 532.641 & 9.0276658561 & 7.4863418111 & 532.637 \\
\hline RUST & 4.8018368080 & 6.97852227960 & 45.590 & 4.8018360187 & 6.9785214459 & 45.577 \\
\hline BKFP & 12.4685775920 & 4.22924313986 & 250.001 & 12.4685767469 & 4.2292421925 & 250.000 \\
\hline ULAG & 6.5173274292 & 3.39762444805 & 44.559 & 6.5173265996 & 3.3976234836 & 44.563 \\
\hline
\end{tabular}

as presented in Table 3 has been developed at epoch 2015.9685 (2015/12/20). First, to assess the accuracy and validity of the transformation parameters, coordinates of some of the stations at epoch 2015.9685 as obtained from GLOBK in this study were transformed to an epoch (2011.00) in which the Office of the Surveyor General of the Federation (OSGoF) last published their coordinates. Tables 6 and 7 present the ECEF and geodetic coordinates and from OSGoF and those obtained using the transformation parameters in Tables 3, 4 and 5, respectively.

\subsection{Statistics for validating transformation parameters}

The accuracy, precision and reliability of the transformation parameters in Table 3 were evaluated by comparing solution obtained from the transformation parameters in ITRF08 and from OSGF using the performance indicators discussed in Sect. 3.5. Figure 4 is the scatter plot in this regard.

The correlation value $R$, root mean square error (RMSE), normalized mean absolute error (NMAE) and reliability index (RI) are at the bottom right: (a) the plot in the $X$, (b) the plot in $Y$ and (c) the plot in $Z$ directions, respectively, of ECEF.

RMSE measures average square error. Zero values or near indicate close match. Therefore, the RMSE $(0.00411 \mathrm{~m})$ of the coordinates from the two data sources is an indication of close match. NMAE assesses the absolute deviation of computed coordinates from GLOBK and that of OSGF. Values of zero or near indicate close match and vice versa. The NMAE $(1.267 \mathrm{E}-10 \mathrm{~m})$ of the coordinates obtained from both sources showed a close match. The RI is an indication of how the two coordinate sources differ from each other; a near one value also indicates a close match. Therefore, 
Fig. 4 a-c Scatter plot of the correlation between coordinates obtained from OSGF and that computed using the developed transformation parameters in Table 3
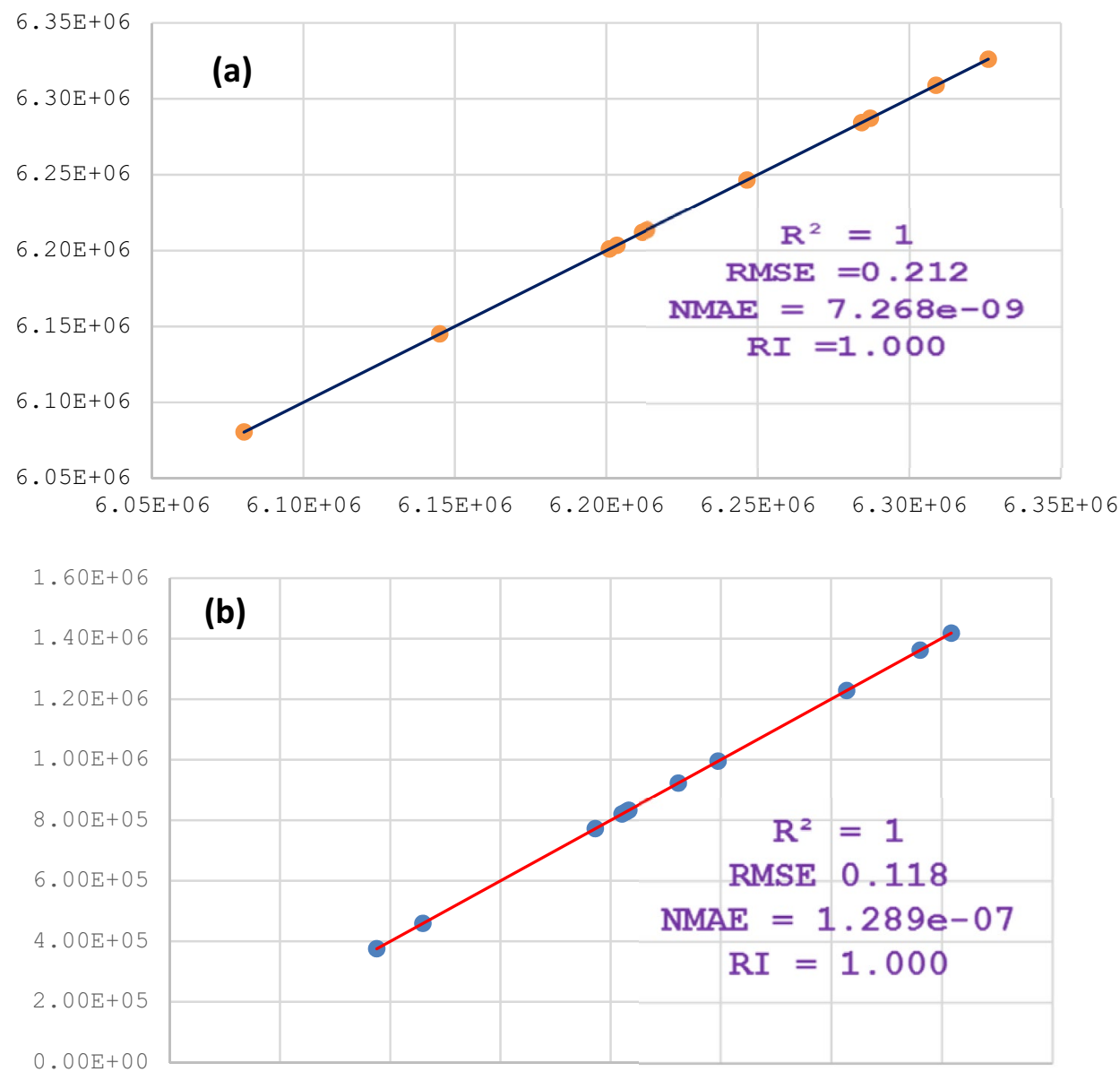

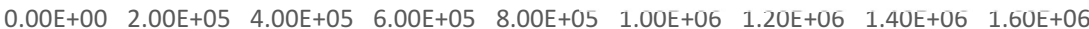

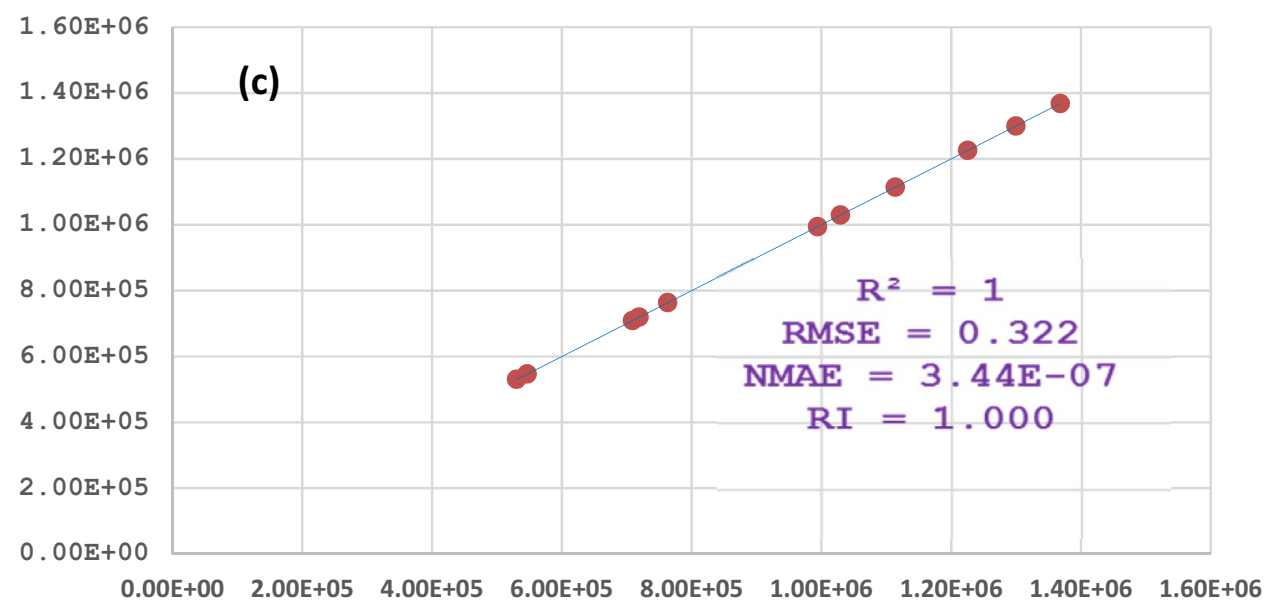

from the two coordinate sources, the two data sources showed close match. The correlation coefficient of the data sources also yielded 1.0, which is a perfect correlation.

Similarly, [1] stated that the origin and scale between ITRF2014 and ITRF2008 are less than $5 \mathrm{~mm}$. Therefore, the transformation parameters for ITRF2014 as developed in this study are also valid since the difference is within $5 \mathrm{~mm}$.

\section{Conclusions and recommendations}

In this study, time-dependent geocentric datum transformation parameters for Nigeria using the NigNet tracking stations have been developed. The accuracy, precision and reliability of the transformation parameters using the $R^{2}$, RMSE, NMAE and RI statistics validate the transformation 
parameters developed in this study. Also the origin and scale differences between ITRF2008 and ITRF2014 found to be within $5 \mathrm{~mm}$ also portray the reliability of the transformation parameters.

The significance of these results is fundamental in providing a variety of applications in areas such as geophysical hazard monitoring and assessment, sea-level monitoring, mining engineering, location based services, land boundary definition (international and local boundaries), environmental mapping, navigation, civil engineering and cadastral applications.

Based on the results of the study, the followings are hereby recommended:

1. The current trend by many countries is the realization of geocentric datum based on ITRF realization. Since the old MINNA datum is filled with many deficits, Nigeria should adopt the ITRF-based geocentric datum.

2. There should be awareness within the geospatial community on the need to move away from the old MINNA datum. This is a task vested on geospatial stakeholders such OSGoF.

Acknowledgements The authors acknowledge the Office of the Surveyor General of Nigeria for providing the data used in this research. Also, the authors thank Mike Floyd of MIT for constantly providing valuable answers to our questions on GAMIT/GLOBK processing. We would also like to thank IGS for providing necessary geodetic products.

\section{Compliance with ethical standards}

Conflict of interest On behalf of all authors, the corresponding author states that there is no conflict of interest.

\section{References}

1. Altamimi Z (2016) The International Terrestrial Reference System and ETRS89: Part II: ITRS \& ETRS89 relationship. UREF Tutorial, San Sebastian, Spain

2. Altamimi Z, Collilieux X, Metivier L (2011) ITRF2008: an improved solution of the international terrestrial reference frame. J Geod 85:457-473. https://doi.org/10.1007/s00190-011-0444-4

3. Altamimi Z, Rebischung P, Métivier L, Collilieux X (2016) ITRF2014: a new release of the international terrestrial reference frame modelling nonlinear station motions. J Geophys Res Solid Earth 121:6109-6131. https://doi.org/10.1002/2016JB013

4. Bawa S, Ojigi LM, Dodo JD (2017) GPS velocity time series of NigNET CORS. Paper Presented at Nigeria Association of Geodesy (NAG) General Assembly/Scientific Conference Rivers State University, Port-Harcourt, Nigeria

5. Bitharis S, Ampatzidis D, Pikridas C (2017) An optimal geodetic dynamic reference frame realization for Greece: methodology and application. Ann Geophys 60(2):S0221. https://doi. org/10.4401/AG-7292
6. Dawson J, Woods A (2010) ITRF to GDA94 coordinate transformations. J Appl Geod 4(2010):189-199. https://doi. org/10.1515/JAG.2010.019

7. Dodo JD, Yakubu TA, Usifoh ES, Bojude A (2011) ITRF 2008 Realization of the Nigerian Geocentric Datum (GDN2012): preliminary results. J Emerg Trends Eng Appl Sci (JETEAS) 2(6):978-986

8. Doukas ID, Ampatzidis D, Kampouris V (2017) The validation of the transformation between an old geodetic reference frame and a modern reference frame, by using external space techniques sites: the case study of the hellenic geodetic reference system of 1987. Bull Geod Sci 23(3):434-444. https://doi. org/10.1590/S1982-21702017000300029

9. Even-Tzur G (2011) Updating the semi-dynamic datum of Israel. Surv Land Inf Sci 71(2):41-47

10. FIG (2014). Reference frames in practice manual. International Federation of Surveyors (FIG) Commission 5 Working Group 5.2 Reference Frames

11. Gill J, Shariff NS, Omar KM, Din AHM, Amin ZM (2016) Development of a time-dependent 3-parameter helmert datum transformation model: a case study for Malaysia. Int Arch Photogramm Remote Sens Spat Inf Sci. https://doi.org/10.5194/ isprs-archives-xlii-4-w1-181-2016

12. Haasdyk J, Janssen $V(2011)$ The many paths to a common ground: a comparison of transformations between GDA94 and ITRF. In: international global navigation satellite systems society IGNSS symposium 2011. University of New South Wales, Sydney, NSW, Australia

13. Haasdyk J, Donnelly N, Harrison C, Rizos C, Roberts C, Stanaway R (2014) Options for modernising the geocentric datum of Australia. In: Proceedings of Research@Locate'14, Canberra, Australia, pp 72-85

14. Herring TA, King RW, Floyd MA, McClusky SC, (2016b) GAMIT GPS analysis software, Release10.6. Department of Earth, Atmospheric, and Planetary Sciences, Massachusetts Institute of Technology

15. Herring TA, King RW, Floyd MA, McClusky SC, (2016a) Introduction to GAMIT/GLOBK. Release 10.6, Department of Earth, Atmospheric, and Planetary Sciences, Massachusetts Institute of Technology

16. Herring TA, King RW, Floyd MA, McClusky SC, (2016c) GLOBK: global Kalman filter VLBI and GPS analysis program, release 10.6. Department of Earth, Atmospheric, and Planetary Sciences, Massachusetts Institute of Technology

17. Isioye OA, Combrinck L, Botai JO (2015) Perfomance evaluation of blind tropospheric delay correction models over Africa. S Afr J Geomat 4(4):502-525. https://doi.org/10.4314/sajg.v4i4.8

18. Janssen V (2017) GDA2020, AUSGeoid2020 and ATRF: an introduction. In: Proceedings of the 22nd Association of Public Authority Surveyors Conference (APAS2017) Shoal Bay, New South Wales, Australia

19. Jatau B, Fernandes RMS, Adebomehin A, Goncalves N (2010) NIGNET-The New Permanent GNSS Network of Nigeria, FIG Congress 2010 Facing the Challenges Building the Capacity Sydney, Australia

20. Kelly KM (2012) Towards implementing dynamic datum data management in GIS. FIG Working Week 2012 knowing to manage the territory, protect the environment, evaluate the cultural heritage Rome, Italy

21. Leggett RW, Williams LR (1981) A reliability index for models. Ecol Model 13:303-312

22. Naibbi Al, Ibrahim SS (2014) An assessment of the existing Continuously Operating Reference Station (CORS) in Nigeria: an exploration using geographic information system (GIS). Am J Geogr Inf Syst 3(4):147-157. https://doi.org/10.5923/j.ajgis .20140304.01

23. Pearson C, McCaffrey R, Elliot JL, Snay R (2010) HDTP 3.0: Software for copying with the coordinate changes associated with 
crustal motion. J Surv Eng 136(2):8090. https://doi.org/10.1061/ ascesu.1943-5428.0000013

24. Pearson P, Snay R (2012) Introducing HTDP 3.1 to transform coordinates across time and spatial reference frames. GPS Solut 17(1):1-17. https://doi.org/10.1007/s10291-012-0255-y

25. Rabah M, Elmewafey M, Farhan MH (2016) Datum maintenance of the main egyptian geodetic control networks by utilizing precise point positioning "PPP" technique. NRIAG J Astron Geophys 5:96-105. https://doi.org/10.1016/j.nrjag.2016.02.003

26. Rabah M, Shaker A, Farhan M (2015) Towards a semi-kinematic datum for egypt. Positioning 6:49-60. https://doi.org/10.4236/ pos.2015.63006

27. Saria E, Calais E, Altamimi Z, Willis P, Farah H (2013) A new velocity field for Africa from combined GPS and DORIS space geodetic solutions: contribution to the definition of the African reference frame (AFREF). J Geophys Res Solid Earth. https://doi. org/10.1002/jgrb.50137

28. Shcherbakov MV, Brebels A, Shcherbakova NL, Tyukov AP, Janovsky TA, Kamaev VA (2013) A survey of forecast error measures. World Appl Sci J 24:171-176. https://doi.org/10.5829/idosi .wasj.2013.24.itimes.80032
29. Soler T, Marshall J (2002) Rigorous transformation of variancecovariance matrices of GPS derived coordinates and velocities. GPS Solut 6:76-90. https://doi.org/10.1007/s10291-002-0019-1

30. Uzodinma VN (2005) VLBL, SLR and GPS data in the Nigerian primary triangulation network-what benefits to future research and national economy. In: Proceedings of the 1st international workshop on geodesy and geodynamics, Nigeria

31. Wang G, Yu J, Ortega J, Saenz G, Burrough T, Neill R (2013) A stable reference frame for the study of ground deformation in the Houston Metropolitan area, texas. J Geod Sci 3(3):188-202. https://doi.org/10.2478/jogs-2013-0021

32. Wei E, Liu J (2014) Precision analysis of IGS long-baseline processing based on GAMIT/GLOBK. Coordinates X:20-24

Publisher's Note Springer Nature remains neutral with regard to jurisdictional claims in published maps and institutional affiliations. 